Article

\title{
Three-Dimensional Paper-Based Microfluidic Analysis Device for Simultaneous Detection of Multiple Biomarkers with a Smartphone
}

\author{
Seung Ho Baek ${ }^{1,+}$, Chanyong Park ${ }^{2,+}$, Jaehyung Jeon ${ }^{1}$ and Sungsu Park $1,2,3, *$ (D) \\ 1 School of Mechanical Engineering, Sungkyunkwan University, Suwon 16419, Korea; \\ steeve777777@gmail.com (S.H.B.); jjh4760.official@gmail.com (J.J.) \\ 2 Department of Biomedical Engineering, Sungkyunkwan University, Suwon 16419, Korea; \\ cksdyd6348@naver.com \\ 3 Biomedical Institute for Convergence at SKKU (BICS), Sungkyunkwan University, Suwon 16419, Korea \\ * Correspondence: nanopark@skku.edu; Tel.: +82-31-290-7431; Fax: +82-31-290-5889 \\ + These authors contributed equally to this work.
}

Received: 25 October 2020; Accepted: 19 November 2020; Published: 21 November 2020

check for updates

\begin{abstract}
Paper-based microfluidic analysis devices ( $\mu$ PADs) have attracted attention as a costeffective platform for point-of-care testing (POCT), food safety, and environmental monitoring. Recently, three-dimensional (3D)- $\mu$ PADs have been developed to improve the performance of $\mu$ PADs. For accurate diagnosis of diseases, however, 3D- $\mu$ PADs need to be developed to simultaneously detect multiple biomarkers. Here, we report a 3D- $\mu$ PADs platform for the detection of multiple biomarkers that can be analyzed and diagnosed with a smartphone. The 3D- $\mu$ PADs were fabricated using a 3D digital light processing printer and consisted of a sample reservoir $(300 \mu \mathrm{L})$ connected to 24 detection zones (of $4 \mathrm{~mm}$ in diameter) through eight microchannels (of $2 \mathrm{~mm}$ in width). With the smartphone application, eight different biomarkers related to various diseases were detectable in concentrations ranging from normal to abnormal conditions: glucose $(0-20 \mathrm{mmol} / \mathrm{L})$, cholesterol $(0-10 \mathrm{mmol} / \mathrm{L})$, albumin $(0-7 \mathrm{~g} / \mathrm{dL})$, alkaline phosphatase $(0-800 \mathrm{U} / \mathrm{L})$, creatinine $(0-500 \mu \mathrm{mol} / \mathrm{L})$, aspartate aminotransferase $(0-800 \mathrm{U} / \mathrm{L})$, alanine aminotransferase $(0-1000 \mathrm{U} / \mathrm{L})$, and urea nitrogen $(0-7.2 \mathrm{mmol} / \mathrm{L})$. These results suggest that $3 \mathrm{D}-\mu \mathrm{PADs}$ can be used as a POCT platform for simultaneous detection of multiple biomarkers.
\end{abstract}

Keywords: paper-based microfluidic device; colorimetric; multiple detection; smartphone application

\section{Introduction}

Paper-based microfluidic analysis devices ( $\mu$ PADs) have attracted attention as a cost-effective tool for point-of-care testing (POCT), food safety, and environmental monitoring [1-4]. They are inexpensive, easy to use, and do not require any external power source. Recently, three-dimensional (3D)- $\mu$ PADs have been developed to improve the performance of two-dimensional (2D)- $\mu$ PADs $[5,6]$. In $3 \mathrm{D}-\mu \mathrm{PADs}$, the combination of lateral and vertical flows shortens analysis times and enables multiple steps, allowing for the integration of various functions [7]. In addition, unlike $2 \mathrm{D}-\mu$ PADs, $3 \mathrm{D}-\mu \mathrm{PADs}$ have the advantage of fewer sample loss since the top of the channel is covered, minimizing evaporation of the sample while the fluid flows through the channel [8]. However, conventional fabrication methods for $3 \mathrm{D}-\mu \mathrm{PADs}$ are labor-intensive and cumbersome because they require the use of additional materials on the exterior, including double-sided sticky tape and adhesive spray [9] to bond two pieces of paper.

Most recently, we have reported on a method to fabricate 3D- $\mu$ PADs for the colorimetric detection of biomarkers using 3D digital light processing (DLP) printing [10]. By exposing photocurable resin to 
be cross-linked with visible light, 3D hydrophobic structures inside and outside the cellulose paper can be printed. They were printed within 2 min without any extra bonding steps and did not show leakage of the solution, which was observed in other 3D- $\mu$ PADs [11,12]. POCT kits can be used to accurately diagnose a specific disease by comprehensively analyzing the detection results of several biomarkers [13]. For example, bone-related diseases may be suspected when very high levels of alkaline phosphatase (ALP) are detected [14] whereas fatty liver or viral hepatitis may be suspected when very high levels of both aspartate aminotransferase (AST) and ALP are detected [15]. To demonstrate the feasibility of the 3D- $\mu$ PADs as a POCT platform, it has to be able to detect more biomarkers at the same time, and the detection results must be more easily and quickly quantified.

Smartphones can provide easy detection and quick analysis results for POCT kits [16-18]. For example, smartphone-based colorimetric and fluorescence analyses have been extensively studied for medical diagnostics [19,20], environmental monitoring [21], and food evaluation [22]. So far, only a small number of biomarkers can be analyzed using a smartphone, making it difficult to accurately diagnose diseases. Therefore, smartphones should be able to analyze multiple samples for accurate diagnoses of diseases $[23,24]$ in the future.

In this study, we report on 3D- $\mu$ PADs for smartphone-based detection of multiple biomarkers. The 3D- $\mu$ PADs were fabricated using a 3D DLP printer with ultraviolet (UV) light. They consisted of a single reservoir connected with 24 detection zones through eight microchannels, allowing eight different biomarkers to be simultaneously and repeatedly detected in a sample. Colored signals from the 3D- $\mu$ PADs were imaged and analyzed using a smartphone.

\section{Materials and Methods}

\subsection{Chemicals}

$\mathrm{D}-(+)-G l u c o s e$, glucose oxidase (GOx) from Aspergillus niger, 4-aminoantipyrine (4-AAP), albumin from human serum, tetrabromophenol blue (TBPB), citric acid, cholesterol (Chol.) ALP, alkaline phosphatase yellow (p-nitrophenyl phosphate), an AST activity assay kit, an alanine aminotransferase (ALT) activity assay kit, a creatinine assay kit, and ethyl alcohol were purchased from Sigma-Aldrich Korea (Seoul, Korea). A urea nitrogen (UN) colorimetric detection kit was purchased from Thermo Fisher Scientific (San Jose, CA, USA). Horseradish peroxidase (HRP), cholesterol oxidase (CO), and cholesterol esterase (CE) were obtained from Toyobo Co. (Osaka, Japan). N-Ethyl-N-(2-hydroxy-3-sulfopropyl)-3,5-dimethylaniline sodium salt monohydrate (MAOS), N-ethyl-N-(2-hydroxy-3-sulfopropyl)-3-methoxyaniline, sodium salt, and dihydrate (ADOS) were purchased from Dojindo (Rockville, MD, USA).

\subsection{Fabrication of $3 D-\mu P A D s$}

The top and bottom structures of the 3D- $\mu$ PADs were separately designed using the Student Edition of Inventor ${ }^{\circledR}$ Professional (Autodesk Inc., San Rafael, CA, USA) and saved as different STL files. The files were then sent to the DLP printer (IM1 ${ }^{\mathrm{TM}}$, Carima Co., Seoul, Korea) using a universal serial bus (USB) drive.

Before printing, a layer of filter paper (Qualitative filter paper: grade 1) from Whatman International Ltd. (Maidstone, UK) was soaked with UV-curable resin (CFY044W, Carima Co.) in a petri dish for $10 \mathrm{~s}$. The resin-soaked paper was moved to a tray filled with resin in the printer. Then, its bottom side was exposed for $2 \mathrm{~s}$ to the UV patterns for the bottom structures projected through the tray (Figure 1b). After the bottom printing, the paper was turned upside down at the same spot of the plate that had been marked and its bottom side was exposed for $60 \mathrm{~s}$ to the ultraviolet (UV) patterns for the upper structures projected through the tray (Figure 1). Next, the printed paper was removed from the tray and then rinsed by $100 \%$ ethyl alcohol for 20 min with gently shaking. Finally, the paper was air-dried for $1 \mathrm{~min}$ at room temperature. 
a

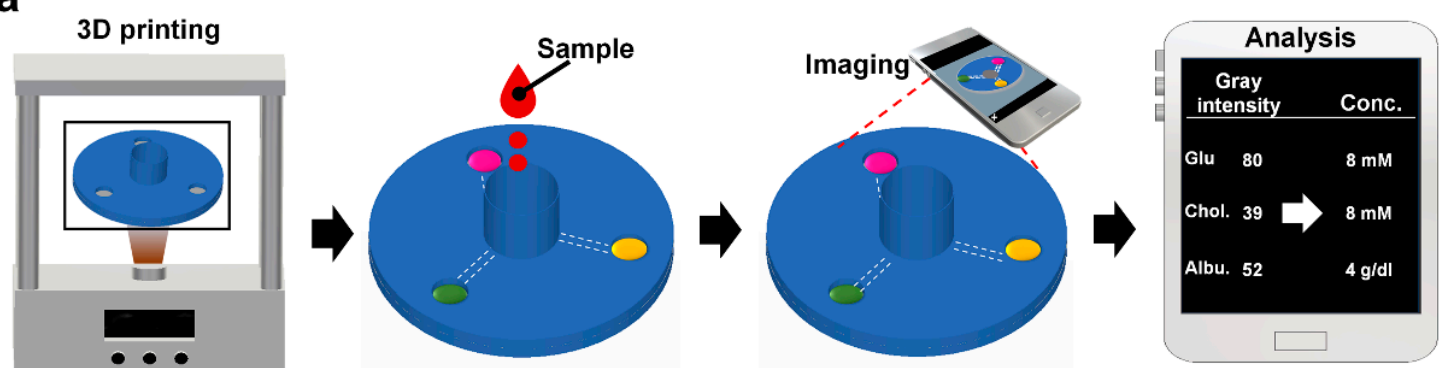

b

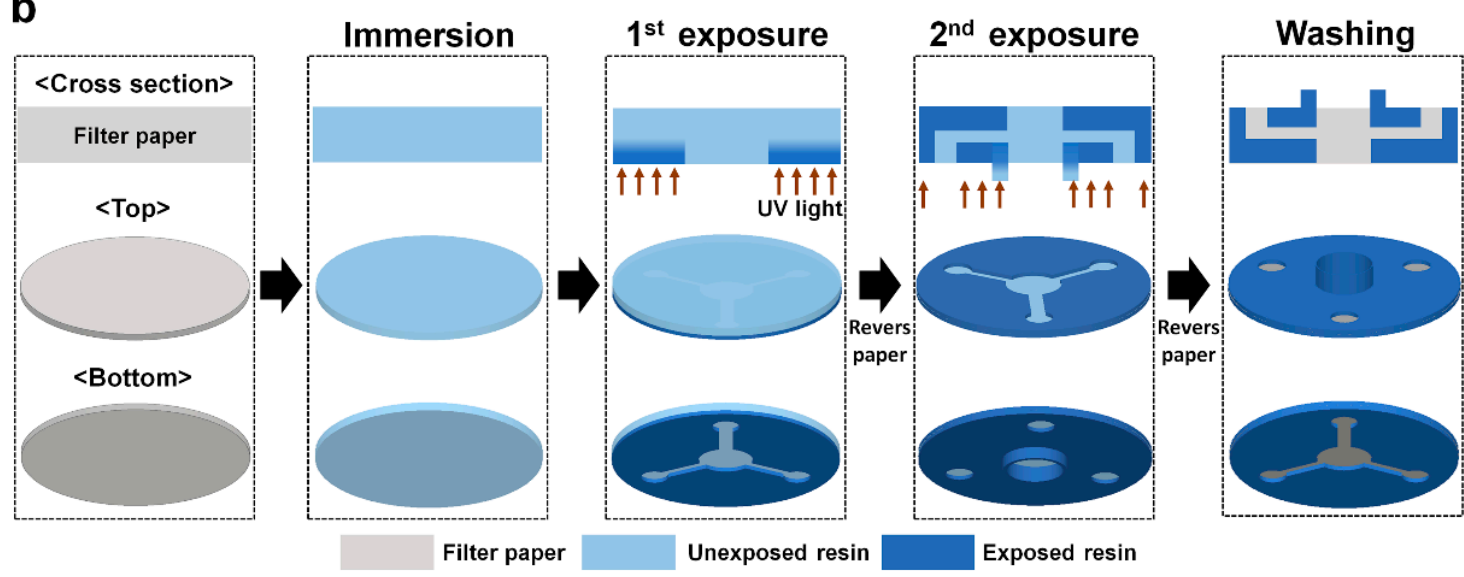

Figure 1. Schematics describing (a) smartphone-based colorimetric detection for multiple biomarkers on the 3D- $\mu$ PADs and (b) 3D DLP printer-based fabrication of the 3D- $\mu$ PADs.

\subsection{Enzyme Fixation}

The reagents for the detection of glucose were prepared by dissolving MAOS (1 mM), 4-AAP $(10 \mathrm{mM}), \mathrm{HRP}(1 \mathrm{mg} / \mathrm{mL})$, and GOx $(10 \mathrm{mg} / \mathrm{mL})$ in phosphate-buffered saline (PBS: $\mathrm{pH} 7.4)$ [23,25]. The reagent for the detection of albumin was prepared by dissolving TBPB $(3.3 \mathrm{mM})$ and citric acid $(0.1 \mathrm{mM})$ in $95 \%$ ethyl alcohol [26]. The reagent used to detect Chol. was prepared by dissolving ADOS (1 mM), CE (14.1 U), CO (10 mg/mL), 4-AAP (10 mM), and HRP (1 mg/mL) in PBS [10]. The reagent used to detect ALP was prepared by dissolving para-nitrophenylphosphate (1.35 $\mathrm{mM})$ in PBS [27]. The remaining AST, ALT, creatinine, and UN enzymes were prepared according to commercial assay kit manuals. Finally, $2 \mu \mathrm{L}$ of each enzyme solution was dropped into its designated detection zone using a micropipette and air-dried for its immobilization at room temperature (RT).

\subsection{Mechanism of Colorimetric Assay}

To test whether the 3D- $\mu$ PADs were able to simultaneously detect multiple biomarkers, eight biomarkers for metabolic diseases such as diabetes and cardiovascular, liver, and renal diseases were selected. Glucose is a biomarker for diabetes [28], cholesterol for cardiovascular disease [29], albumin, ALT, ALP, and AST for liver diseases [30], albumin, UN, and creatinine for renal diseases [31]. Colorimetric reaction through enzymes is the core mechanism of multiple biomarkers. For colorimetric detection of glucose, the GOx precipitated in the detection zone, which oxidizes glucose to gluconic acid while generating hydrogen peroxide. Another enzyme occupied in the detection zone, known as HRP, converted hydrogen peroxide into oxygen. Simultaneously, 4-AAP was reacted with MAOS. At the end of the HRP-mediated reaction, a blue product was formed [23]. For colorimetric detection of albumin, the TBPB precipitated in the detection zone, which reacts like a $\mathrm{pH}$ indicator. The higher the amount of albumin, the more it reacts with TBPB, causing a color change from yellow to blue as the $\mathrm{pH}$ increases [32]. For colorimetric detection of cholesterol, the $\mathrm{CO}$ and $\mathrm{CE}$ precipitated in the detection zone, which oxidizes cholesterol to Chol-4-en-3-one while generating hydrogen peroxide. 
Another enzyme occupied in the detection zone, HRP, converted hydrogen peroxide into oxygen. Simultaneously, 4-AAP reacted with ADOS. At the end of the HRP-mediated reaction, a pink product was formed. For colorimetric detection of ALP, the para-nitrophenylphosphate precipitated in the detection zone. As albumin and para-nitrophenylphosphate react, a yellow product, known as p-nitrophenylate, was formed. The remaining AST, ALT, creatinine, and UN reaction follows the commercial assay kit mechanism.

\subsection{Detection of Biomarkers in PBS}

To obtain a dose-response curve for biomarkers, standard solutions of the biomarkers were prepared by mixing the stock solution of each biomarker with different volumes of PBS ( $\mathrm{pH}$ 7.4). The stock solution was prepared by dissolving a certain concentration of a biomarker in PBS. The concentrations of the standard solutions for the biomarkers varied, depending on the optimal detection range of each biomarker: $0-20 \mathrm{mmol} / \mathrm{L}$ for glucose, $0-10 \mathrm{mmol} / \mathrm{L}$ for Chol., $0-7 \mathrm{~g} / \mathrm{dL}$ for albumin, 0-800 U/L for ALP, 0-500 $\mu \mathrm{mol} / \mathrm{L}$ for creatinine, 0-800 U/L for AST, 0-1000 U/L for ALT, and $0-7.2 \mathrm{mmol} / \mathrm{L}$ for $\mathrm{UN}$. To generate the standard curve of a biomarker, $10 \mu \mathrm{L}$ of the standard solution of the biomarker was dropped on the detection zone. At $1 \mathrm{~min}$ after the dropping, the gray intensity in the detection zone was measured using Image (NIH, Bethesda, MD, USA).

To simultaneously detect the biomarkers in PBS, a mixture of the biomarkers at different concentrations was prepared by mixing their stock solutions with PBS at various ratios. Furthermore, $300 \mu \mathrm{L}$ of the mixture was dropped onto the sample reservoir of the 3D- $\mu$ PADs. At 3 min after the dropping, the gray intensity of each detection zone was measured using ImageJ.

\subsection{Operation of the Smartphone Application}

Once the names of the biomarkers were marked on the start screen, the linearization equation calculated from the dose-response curve was specified with its normal range. Images of the control and test samples were imported into the application. The detection zones in the images were designated as circles. The gray intensity in each circle was measured. Then, the gray intensity value for each biomarker was obtained by subtracting the gray intensity of the sample from the intensity of the control. Eventually, the concentration and level (low to high) of the eight biomarkers appeared.

\subsection{Photo Box for Capturing Images from $3 D-\mu P A D s$}

To reduce the effect of reflecting light on the measurement of the color intensity of the detection zones [33], a switchable white light bulb was installed in a black cardboard box (measuring $90 \mathrm{~mm}$ by $60 \mathrm{~mm}$ by $40 \mathrm{~mm}$ in width, length, and height, respectively) with a sliding door, allowing the $3 \mathrm{D}-\mu \mathrm{PADs}$ to be inserted into the box.

\section{Results and Discussion}

\subsection{Effect of Exposure Time on the Height of Cured Resin}

For fast printing, UV light instead of visible light [8] was used to cure the resin to fabricate 3D- $\mu$ PADs. Since the hydrophilic surface of paper is changed to a hydrophobic one with curing by UV light, the degree of curing can be estimated by changing the color of the cross section of the paper with red ink when the ink was dropped onto the paper. As shown in Figure 2a, the cross section of the uncured paper was completely wet with red ink. At $1 \mathrm{~s}, \sim 50 \mu \mathrm{m}$ of the paper was wet with the ink, indicating that part of it was cross-linked. This uniformity was further supported by the scanning electron microscope images showing fibrous structures in uncured parts, which disappeared in the cured parts (Figure S1). At $2 \mathrm{~s}, \sim 90 \mu \mathrm{m}$ of the paper was cured. At $3 \mathrm{~s}$, the paper was not wet with the ink, exhibiting only the white color of the cross-linked resin. The thickness of the cured paper was $\sim 200 \mu \mathrm{m}$, which is greater than the thickness of the original paper $(180 \mu \mathrm{m})$, indicating that the paper was slightly overexposed. Based on the results, the optimal exposure time for fabricating the bottom 
structures inside the paper was chosen to be $2 \mathrm{~s}$, which half of the paper was cured. The height of the structure cured by the resin in this study increased with rising exposure time. This is because the amount of cross-linked resin increases as the UV exposure time increases [10,20]. In fact, the reservoir at $5 \mathrm{~mm}$ height was printed by overexposing the paper for $60 \mathrm{~s}$ (Figure 2b). It takes about $90 \mathrm{~s}$ to print the top and bottom structures of the paper and remove uncured resin from the paper and the printing costs less than a dollar per device when the devices are mass produced. The results suggest that our new method is highly suitable for the rapid production of 3D- $\mu$ PADs.

a

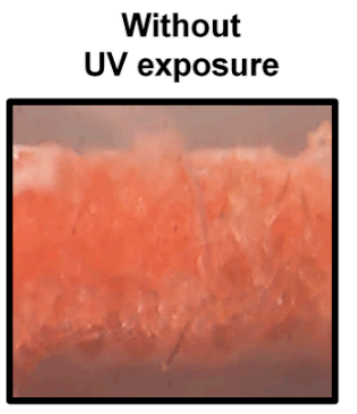

b

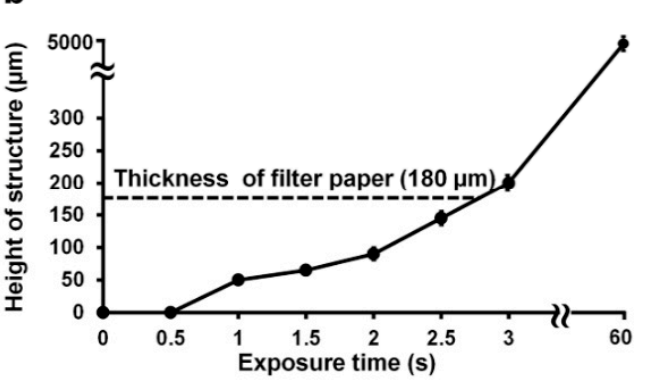

d

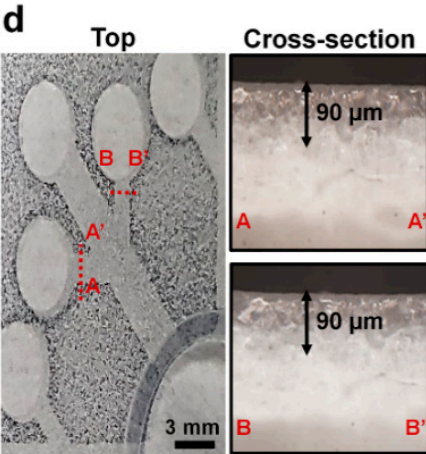

With UV exposure (s)

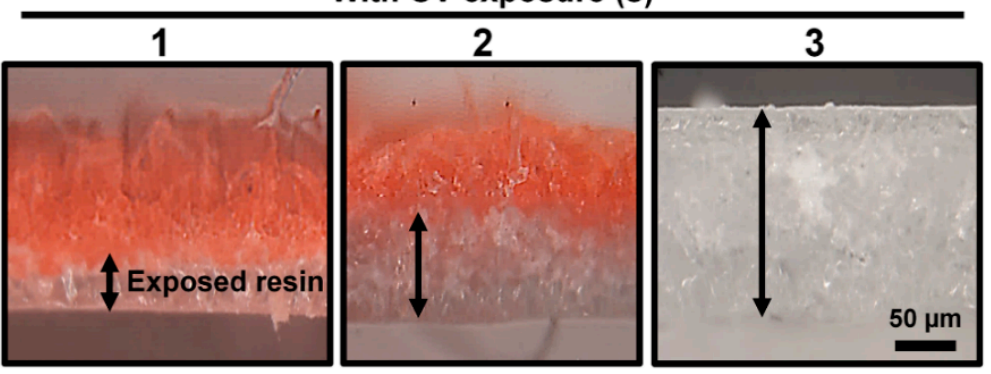

C

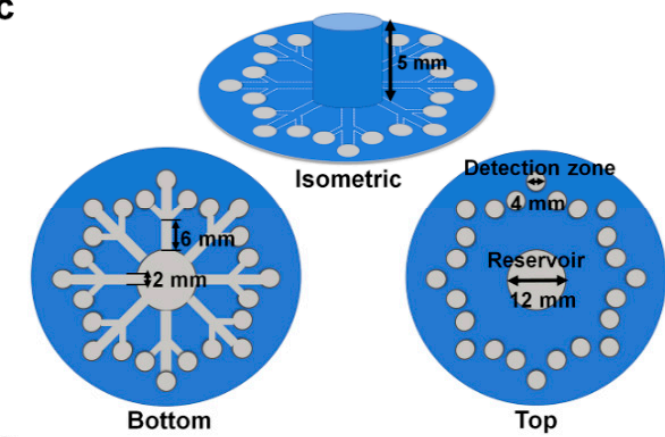

e

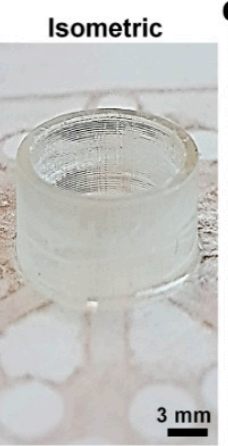

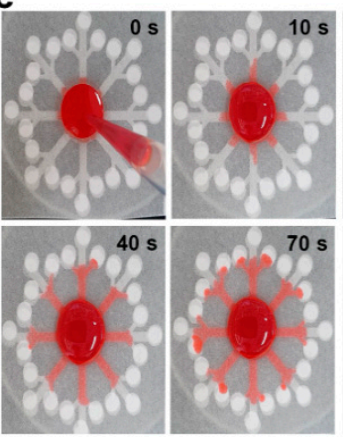

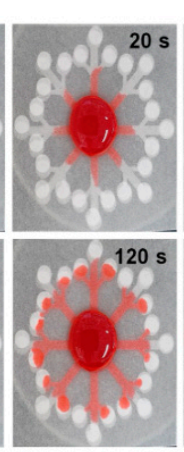

Figure 2. Control of cross-linked structures and flow inside filter paper. (a) Cross-sectional views of the resin inside the paper with and without ultraviolet (UV) exposure at different times (1-3 s). The black arrow indicates exposed resin areas. (b) Height of cross-linked resin structures inside the paper at different exposure times (0-60 s). The dotted black line indicates the thickness of the paper. (c) Bottom, top, and isometric views with dimensions of the design for the 3D- $\mu$ PADs. (d) Cross-sectional images of two different channels and an isometric image of a sample reservoir. The black arrow indicates exposed resin that is the height of the structure. (e) Flow distribution in the 3D- $\mu$ PADs at different times (0-150 s). For visualization of flow, red ink $(300 \mu \mathrm{L})$ was added into the sample reservoir (center).

The 3D- $\mu$ PADs consist of a sample reservoir (diameter: $12 \mathrm{~mm}$, height: $5 \mathrm{~mm}$ ) in the center connected with 24 detection zones (diameter: $4 \mathrm{~mm}$ ) through eight channels (width: $2 \mathrm{~mm}$, length: $6 \mathrm{~mm}$ ) (Figure 2c). At least $300 \mu \mathrm{L}$ of solution needed to be loaded into the sample reservoir to fully wet all the detection zones. By printing the reservoir $5 \mathrm{~mm}$ high, a large amount of sample solution up 
to $500 \mu \mathrm{L}$ can be loaded into the device without overflow, which was often observed in 2D- $\mu$ PADs [34]. With this increase, it is suggested that the 3D- $\mu$ PADs are highly suitable for handling a sample in a large volume, thereby enabling analysis of multiple biomarkers.

\subsection{Uniform Distribution of Fluid on $3 D-\mu P A D s$}

The flow rate of a sample solution affects signal generation in 3D- $\mu$ PADs [35]. Therefore, the channel size in the 3D- $\mu$ PADs should be uniform to reduce signal variation in the 3D- $\mu$ PADs. The quality of the printed structures in the 3D- MPADs was examined by measuring the height of the channels in the 3D- PADs (Figure 2d). The average channel height was $90 \pm 1.2 \mu \mathrm{m}(n=48)$, indicating that all channels of the 3D- $\mu$ PADs were uniformly fabricated.

To test whether solutions in the reservoir reached the detection zones at a similar flow rate, the flow speed of ink in each channel was measured after dropping $300 \mu \mathrm{L}$ of red ink into the reservoir over the channels in the 3D- $\mu$ PADs at different times (0-150 s) (Figure 2e). It took $150 \mathrm{~s}$ for the ink to travel $20 \mathrm{~mm}$, the distance between the detection zone and the center of the reservoir, corresponding to a speed of $0.13 \mathrm{~mm} / \mathrm{s}$. The ink in all 24 channels traveled through the paper at a similar speed. Taken together, our results suggest that our printing method can rapidly fabricate 3D- $\mu$ PADs with high accuracy.

\subsection{Quantitative Detection of Analytes in PBS}

A dose-response curve for each biomarker was obtained by quantifying the gray intensity in the detection zones at different concentrations of biomarkers, as shown in Figure 3. Five experiments were repeated to draw a dose-response curve, and the error of this result was expressed as a standard deviation. The gray intensity was proportional to the biomarker concentration. The shape of the dose-response curve of all biomarkers follows a quadratic parabolic equation with a saturation point, and the reliability $\left(\mathrm{R}^{2}\right)$ values were all $>0.96$. According to the dose-response curves, the limits of detection were $0.3 \mathrm{mmol} / \mathrm{L}$ for glucose, $0.3 \mathrm{mmol} / \mathrm{L}$ for cholesterol, $0.1 \mathrm{~g} / \mathrm{dL}$ for albumin, $10 \mathrm{U} / \mathrm{L}$ for ALP, $40 \mu \mathrm{mol} / \mathrm{L}$ for creatinine, $10 \mathrm{U} / \mathrm{L}$ for AST, $50 \mathrm{U} / \mathrm{L}$ for ALT, and $0.04 \mathrm{mmol} / \mathrm{L}$ for UN. The linear range of each biomarker was obtained from the dose-response curve, including its respective normal range (2.5-5.8 mmol/L for glucose [25,36], 5.2-6.2 mmol/L for cholesterol [37], 3.4-5.4 g/dL for albumin [38], 44-147 U/L for ALP [39], 45-90 $\mu \mathrm{mol} / \mathrm{L}$ for creatinine [40], 0-40 U/L for AST [41], 7-56 U/L for ALT [42], and 2.5-7 mmol/L for UN [43]) Coefficient of variance (CV) values at each concentration of all biomarkers were less than $10 \%$, showing good reproducibility. These results suggest that the $3 \mathrm{D}-\mu \mathrm{PADs}$ are quite useful for quantification of all eight biomarkers as well as for the diagnosis of metabolic diseases.

\subsection{Uniform Signal at Each Detection Zone on $3 D-\mu P A D s$}

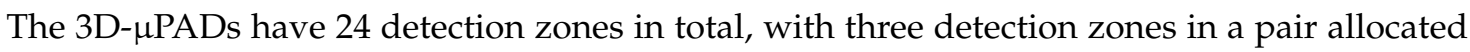
to each biomarker, allowing the biomarker to be measured three times (Figure 4a). When a sample solution in PBS containing all eight biomarkers was loaded into the sample reservoir, similar color intensities were observed from the detection zones for each biomarker (Figure $4 b-i)$. Analysis of gray intensities in the zones showed that there were low variations in the three detection zones, which was supported by coefficients of variation of $<5 \%$ (being $2.7 \%$ for glucose, $3 \%$ for cholesterol, $4 \%$ for albumin, $4.3 \%$ for ALP, $4.8 \%$ for creatinine, $4.6 \%$ for AST, $1.2 \%$ for ALT, and 1.1\% for UN). These low variations in the detection zone could be due to the relatively higher accuracy in printing channel structures (Figure 2d) accompanied by a uniform flow speed (Figure 2e) compared to conventional $\mu$ PADs [44-46]. 

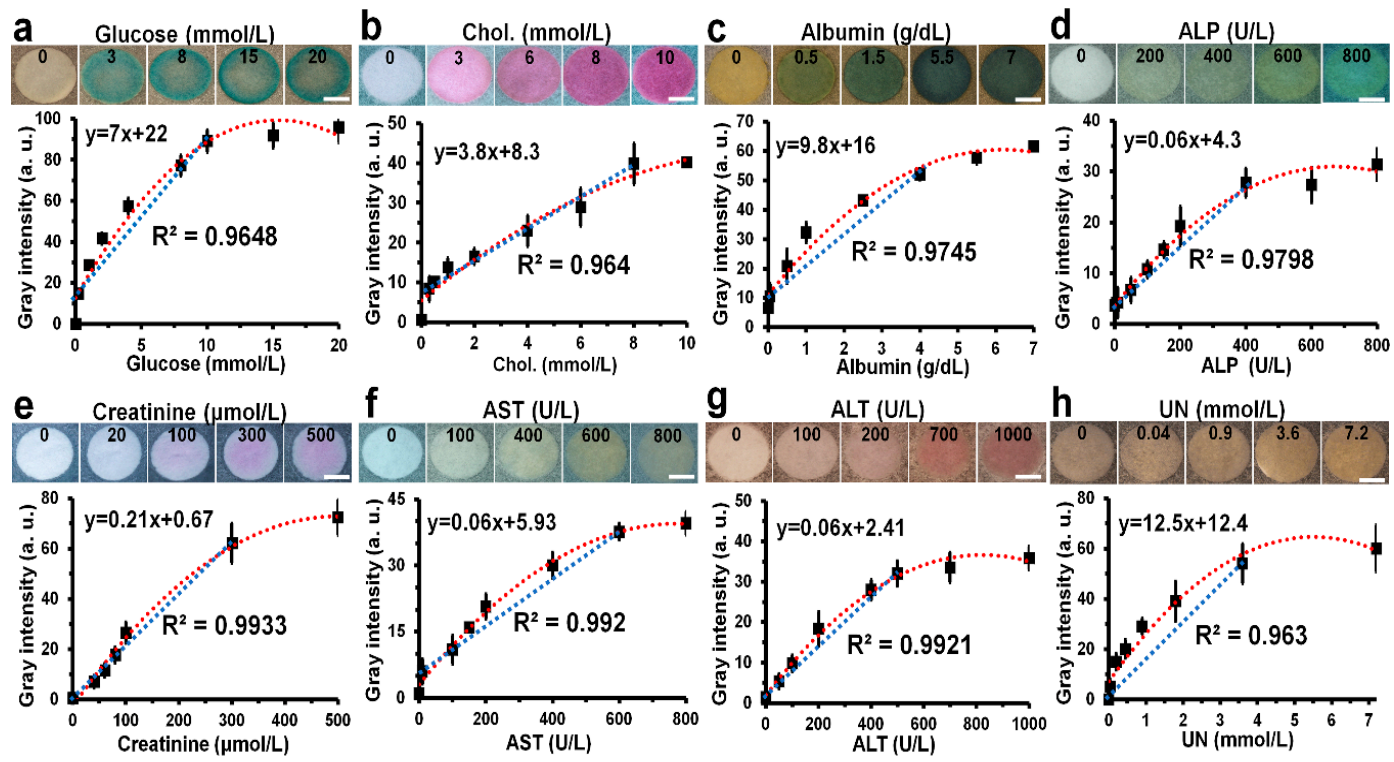

Figure 3. Colorimetric detection of eight biomarkers (glucose, Chol., albumin, ALP, creatinine, AST, ALT, and UN) in PBS. (a-h) Dose-response curves were calculated from the data obtained by 15 repeated uses of each analyte at different concentrations and representative images of the detection zones reacted with various concentrations of a single biomarker: glucose $(0-20 \mathrm{mmol} / \mathrm{L}), \mathrm{Chol} .(0-10 \mathrm{mmol} / \mathrm{L})$, albumin (0-7 g/dL), ALP (0-800 U/L), creatinine (0-500 $\mu \mathrm{mol} / \mathrm{L})$, AST (0-800 U/L), ALT (0-1000 U/L), and $\mathrm{UN}(0-7 \mathrm{mmol} / \mathrm{L})$. (Scale bar: $4 \mathrm{~mm}$. a.u.: arbitrary units.).

a

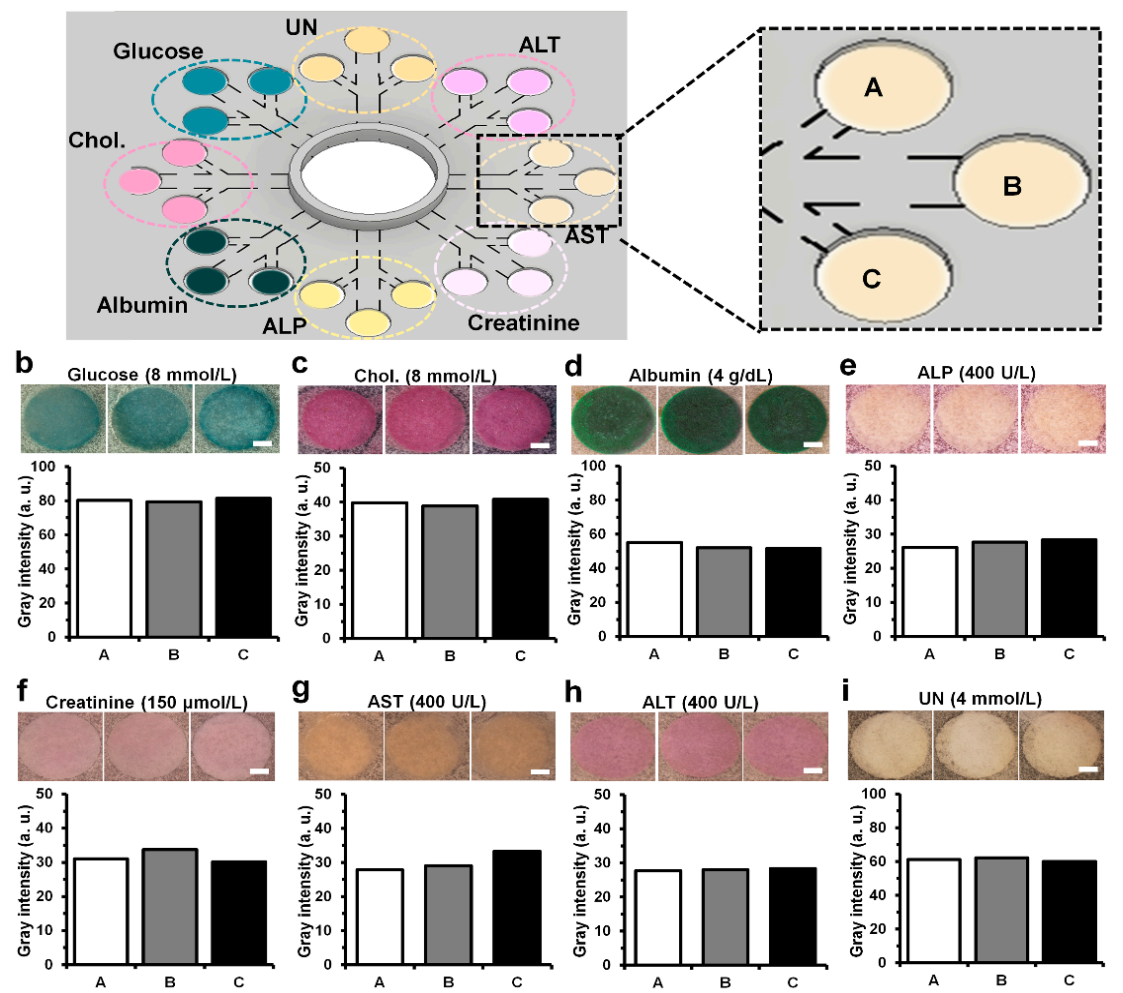

Figure 4. Uniformity comparison of colorimetric detection of eight biomarkers (glucose, cholesterol, albumin, ALP, creatinine, AST, ALT, and UN) at the concentration in PBS. (a) Schematics of the 3D- $\mu$ PADs for simultaneous detection of the eight biomarkers. The 3D- $\mu$ PADs have three detection zones (A, B, and C) per each biomarker. (b-i) Gray intensities calculated from the data obtained by three repeated uses of each analyte at the concentrations and representative images of the detection zones reacted with 
the concentrations of a single biomarker: glucose $(8 \mathrm{mmol} / \mathrm{L})$, cholesterol $(8 \mathrm{mmol} / \mathrm{L})$, albumin $(4 \mathrm{~g} / \mathrm{dL})$, ALP (400 U/L), creatinine (150 $\mu \mathrm{mol} / \mathrm{L})$, AST (400 U/L), ALT (400 U/L), and UN (4 mmol/L). (Scale bar:

$1 \mathrm{~mm}$. a.u.: arbitrary units. $n=3)$.

\subsection{Simultaneous Detection of Multiple Biomarkers in PBS Using the Smartphone Application}

For fast and convenient detection of multiple biomarkers on the 3D- $\mu$ PADs, a smartphone application was developed and tested with $300 \mu \mathrm{L}$ of PBS containing the eight biomarkers $(8 \mathrm{mmol} / \mathrm{L}$ for glucose, $8 \mathrm{mmol} / \mathrm{L}$ for cholesterol, $4 \mathrm{~g} / \mathrm{dL}$ for albumin, $400 \mathrm{U} / \mathrm{L}$ for ALP, $150 \mu \mathrm{mol} / \mathrm{L}$ for creatinine, $400 \mathrm{U} / \mathrm{L}$ for AST, $400 \mathrm{U} / \mathrm{L}$ for ALT, and $4 \mathrm{mmol} / \mathrm{L}$ for UN). Once the colors were generated from the detection zones on the 3D- $\mu$ PADs, which took $\sim 3$ min (Figure $5 a, b$ ), the image of the 3D- $\mu$ PADs was captured in the photo box using the smartphone (Figure $5 \mathrm{c}-\mathrm{e}$ ). Then, the gray intensities in the detection zones were measured and the concentrations of the biomarkers were calculated by using the application (Figure $5 \mathrm{f}-\mathrm{h}$ ). The concentrations obtained by the 3D- $\mu$ PADs with the smartphone application were not significantly different from the original concentrations in PBS, which was indicated by a relative error of $<5 \%$ (Table 1). These concentrations were similar to those obtained by ImageJ, exhibiting a relative error of $<7 \%$ (Table 1). Depending on the concentration, the level of the biomarkers in the sample was determined to be low, normal, or high (Figure 5h). Similarly, the application could be used for the simultaneous detection of multiple biomarkers in serum samples (Figure S2). This was demonstrated by small differences between the gray intensities of the detection zones and a serum sample obtained by ImageJ and the application (Table S1). These results suggest that the 3D- $\mu$ PADs with the application are highly useful for multiple detections of biomarkers and convenient self-diagnosis of diseases.

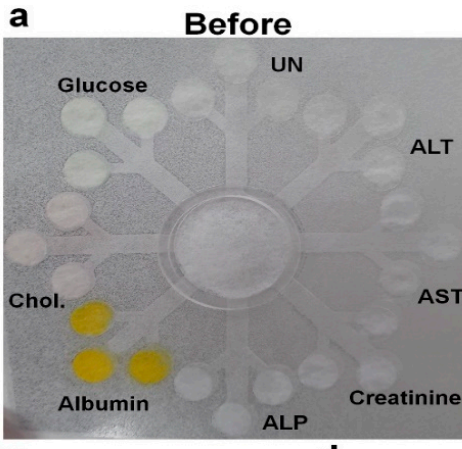

d

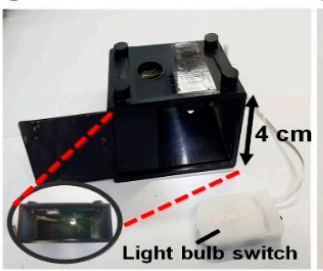

f

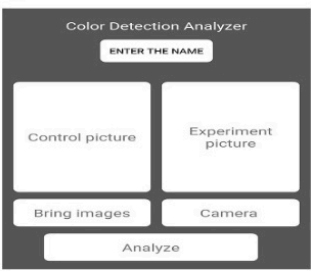

g b

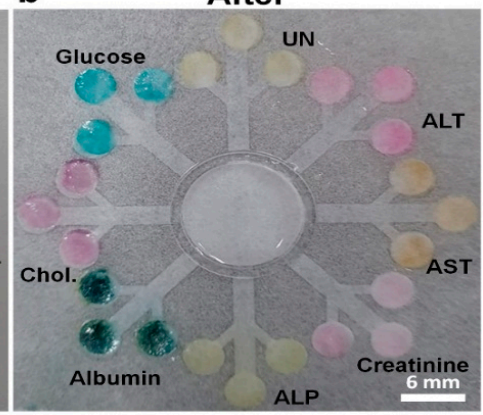

e
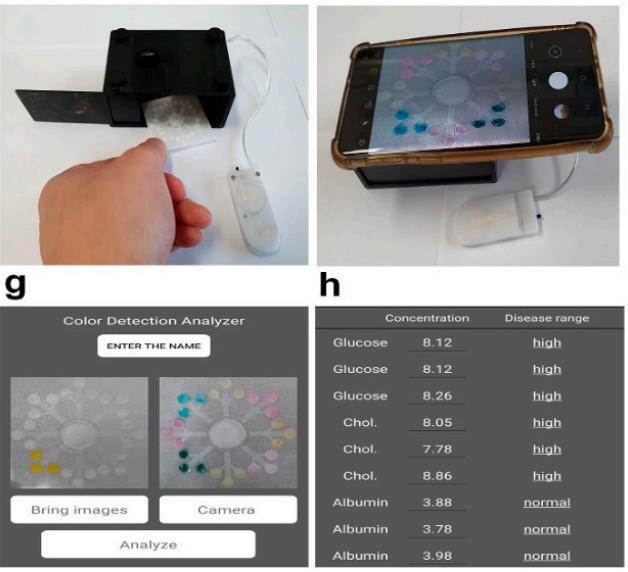

h

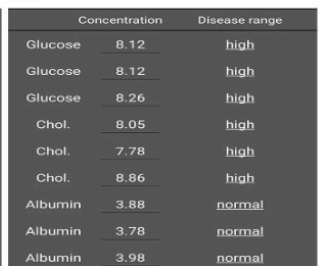

Figure 5. Schematics for detection of multiple biomarkers on the 3D- $\mu$ PADs in the photo box using the smartphone application. (a) Each enzyme is fixed on each detection zone before loading the sample. (b) Simultaneous detection of multiple biomarkers including $8 \mathrm{mmol} / \mathrm{L}$ for glucose, $8 \mathrm{mmol} / \mathrm{L}$ for Chol., $4 \mathrm{~g} / \mathrm{dL}$ for albumin, $400 \mathrm{U} / \mathrm{L}$ for ALP, $150 \mu \mathrm{mol} / \mathrm{L}$ for creatinine, $400 \mathrm{U} / \mathrm{L}$ for AST, $400 \mathrm{U} / \mathrm{L}$ for ALT, and $4 \mathrm{mmol} / \mathrm{L}$ for UN in PBS. (c-h) Using the smartphone application to measure the concentration and normality of each biomarker. 
Table 1. Concentrations of biomarkers based on gray intensities measured by ImageJ and the smartphone application with the photo box. Biomarkers at different concentrations were prepared by dissolving known concentrations of the biomarkers in PBS before testing. The mean and standard deviation of each biomarker were obtained from the measurement of gray intensity on three different $\mu$ PADs devices with nine detection zones. Device-to-device relative standard deviation (RSD) was less than $5 \%$ (1.2\% for glucose, $3.2 \%$ for cholesterol, $4.7 \%$ for albumin, $2.8 \%$ for ALP, 3.7\% for creatinine, $0.9 \%$ for AST, $4.4 \%$ for ALT, and $3.1 \%$ for UN).

\begin{tabular}{|c|c|c|c|c|}
\hline \multirow{2}{*}{$\begin{array}{c}\text { Biomarker } \\
\text { Concentration }[A]\end{array}$} & \multicolumn{2}{|c|}{ ImageJ } & \multicolumn{2}{|c|}{ Smartphone Application } \\
\hline & $\begin{array}{c}\text { Concentration } \\
{[B] \perp}\end{array}$ & $\begin{array}{l}\text { Relative Error (\%) } \\
{[(|\mathrm{A}-\mathrm{B}| / \mathrm{A}) \times 100]}\end{array}$ & $\begin{array}{c}\text { Concentration } \\
{[C] \perp}\end{array}$ & $\begin{array}{l}\text { Relative Error }(\%) \\
{[(|A-C| / A) \times 100]}\end{array}$ \\
\hline $\begin{array}{l}\text { High glucose } \\
(8 \mathrm{mmole} / \mathrm{L})\end{array}$ & $8.3 \pm 0.1(\mathrm{mmole} / \mathrm{L})$ & 3.8 & $8.2 \pm 0.2(\mathrm{mmole} / \mathrm{L})$ & 2.1 \\
\hline $\begin{array}{l}\text { High Cholesterol } \\
\text { (8 mmole/L) }\end{array}$ & $8.5 \pm 0.3(\mathrm{mmole} / \mathrm{L})$ & 6.3 & $8.2 \pm 0.5(\mathrm{mmole} / \mathrm{L})$ & 2.9 \\
\hline $\begin{array}{l}\text { Normal albumin } \\
(4 \mathrm{~g} / \mathrm{dL})\end{array}$ & $3.8 \pm 0.2(\mathrm{~g} / \mathrm{dL})$ & 5.7 & $3.9 \pm 0.11(\mathrm{~g} / \mathrm{dL})$ & 3.1 \\
\hline $\begin{array}{c}\text { High ALP (400 } \\
\text { U/L) }\end{array}$ & $386.6 \pm 20.2(\mathrm{U} / \mathrm{L})$ & 3.4 & $402.2 \pm 18(\mathrm{U} / \mathrm{L})$ & 0.6 \\
\hline $\begin{array}{l}\text { High creatinine } \\
(150 \mu \mathrm{mole} / \mathrm{L})\end{array}$ & $147.3 \pm 8.9(\mu$ mole $/ \mathrm{L})$ & 1.8 & $150.6 \pm 7.4(\mu \mathrm{mole} / \mathrm{L})$ & 0.5 \\
\hline $\begin{array}{l}\text { High AST } \\
(400 \mathrm{U} / \mathrm{L})\end{array}$ & $402.6 \pm 47.8(\mathrm{U} / \mathrm{L})$ & 0.6 & $395.8 \pm 34.7(\mathrm{U} / \mathrm{L})$ & 1.1 \\
\hline $\begin{array}{l}\text { High ALT (400 } \\
\text { U/L) }\end{array}$ & $426.8 \pm 5.7(\mathrm{U} / \mathrm{L})$ & 6.7 & $415.7 \pm 9.6(\mathrm{U} / \mathrm{L})$ & 3.9 \\
\hline $\begin{array}{l}\text { Normal UN } \\
(4 \text { mmole/L) }\end{array}$ & $3.9 \pm 0.1(\mathrm{mmole} / \mathrm{L})$ & 2.5 & $4 \pm 0.1(\mathrm{mmole} / \mathrm{L})$ & 0.1 \\
\hline
\end{tabular}

\section{Conclusions}

In this study, 3D- $\mu$ PADs were fabricated using a 3D DLP printer for multiple detections. The reservoir on 3D- $\mu$ PADs can store enough sample for multiple detections. Sequentially, the concentration can be obtained three times per biomarker in one experiment to reduce errors. Eight biomarkers (glucose, cholesterol, albumin, ALP, creatinine, AST, ALT, and UN) in PBS and serum could be detected simultaneously on the 3D- $\mu$ PADs through a smartphone. In this experiment, the size of the detection zone was set to $4 \mathrm{~mm}$ to easily analyze the selected area using a smartphone camera. However, using a high-quality smartphone, we could minimize the detection zone. This also reduces the amount of the sample, which leads to the detection of more biomarkers. In previous research, we succeeded in integrating plasma separation membrane with 3D- $\mu$ PADs [20]. This suggests that the 3D- $\mu$ PADs with the plasma separation membrane will allow patients to easily diagnose diseases remotely using a smartphone at home in the future.

Supplementary Materials: The following are available online at http://www.mdpi.com/2079-6374/10/11/187/s1, Table S1: Comparison of gray scale intensities measured by ImageJ (NIH, Bethesda, MD, USA) and a smartphone application. The application was custom-made for the study. The gray intensity of each detection zone was measured using either ImageJ or an application of the smartphone. Biomarkers at different concentrations in serum were prepared using Lyphocheck Assayed Chemistry Control (Bio-Rad, Richmond, CA, USA). In details, a mixture of serum containing the biomarkers at different concentrations were prepared by carefully mixing human serum Lyphocheks Assayed Chemistry Control level 1 and level 2 containing different concentrations of each biomarker. Then, $5 \mathrm{~mL}$ of deionized water was added into the mixture to adjust the concentrations of the biomarkers. After the addition, the mixture was gently shaken without generating bubbles and $300 \mu \mathrm{L}$ of the mixture were dropped onto the sample reservoir of the 3D- $\mu$ PADs. Chol.: cholesterol. ALP: alkaline phosphatase. AST: aspartate aminotransferase. UN: urea nitrogen. (a.u.: arbitrary units.). Figure S1: Surface image of cellulose fiber in paper showing changes caused by the photocurable resin during 3D digital light printing (DLP) and ethanol washing. (a) The bare filter paper. (b) The filter paper soaked with resin. (c) 10 times of ethanol washing after the filter paper was soaked with resin (d) The fully cured paper. (Scale bar: $50 \mu \mathrm{m}$. magnification: 100X). 
Images were obtained with Scanning electron microscopy (JSM-6700F, JEOL, Tokyo, Japan). Figure S2: Multiple detection on the 3D- $\mu$ PADs using a serum sample. (a) Color difference between the PBS sample and spiked serum sample in tubes. (b) Each enzyme was fixed on each detection zone before testing. (c). Detection of multiple biomarkers by dropping the sample $(300 \mu \mathrm{L})$ including $8 \mathrm{mmol} / \mathrm{L}$ for glucose, $8 \mathrm{mmol} / \mathrm{L}$ for Chol., $4 \mathrm{~g} / \mathrm{dL}$ for albumin, $400 \mathrm{U} / \mathrm{L}$ for ALP, $150 \mu \mathrm{mol} / \mathrm{L}$ for creatinine, $400 \mathrm{U} / \mathrm{L}$ for AST, $400 \mathrm{U} / \mathrm{L}$ for ALT, $4 \mathrm{mmol} / \mathrm{L}$ for UN in spike serum sample.

Author Contributions: Conceptualization, S.H.B., C.P., and S.P. Methodology, S.H.B. and C.P. Software, S.H.B. Data Curation, J.J. and C.P. Writing (Original Draft Preparation), S.H.B. and C.P. Writing (Review and Editing), S.H.B., C.P., and S.P. Supervision, S.P. All authors have read and agreed to the published version of the manuscript.

Funding: This research was equally supported by the BioNano Health-Guard Research Center as a Global Frontier Project (H-GUARD-2018M3A6B2057299) and National Research Foundation(NRF) grant (2018R1A2B2002066) funded by the Ministry of Science and ICT (MSIT) of Korea and the Technology Innovation Program for in-situ virus detection and analysis (20012215) funded By the Ministry of Trade, Industry \& Energy (MOTIE) of Korea.

Conflicts of Interest: The authors declare no conflict of interest.

\section{References}

1. Rozand, C. Paper-based analytical devices for point-of-care infectious disease testing. Eur. J. Clin. Microbiol. 2014, 33, 147-156. [CrossRef]

2. Hu, J.; Wang, S.; Wang, L.; Li, F.; Pingguan-Murphy, B.; Lu, T.J.; Xu, F. Advances in paper-based point-of-care diagnostics. Biosens. Bioelectron. 2014, 54, 585-597. [CrossRef] [PubMed]

3. Tian, T.; Wei, X.; Jia, S.; Zhang, R.; Li, J.; Zhu, Z.; Zhang, H.; Ma, Y.; Lin, Z.; Yang, C.J. Integration of target responsive hydrogel with cascaded enzymatic reactions and microfluidic paper-based analytic devices ( $\mu$ PADs) for point-of-care testing (POCT). Biosens. Bioelectron. 2016, 77, 537-542. [CrossRef] [PubMed]

4. Wang, X.; Hu, L. Enzymatic Strips for Detection of Serum Total Cholesterol with Point-of-Care Testing (POCT) Devices: Current Status and Future Prospect. J. Electrochem. Soc. 2020, 167, 037535. [CrossRef]

5. Ge, L.; Yan, J.; Song, X.; Yan, M.; Ge, S.; Yu, J. Three-dimensional paper-based electrochemiluminescence immunodevice for multiplexed measurement of biomarkers and point-of-care testing. Biomaterials 2012, 33, 1024-1031. [CrossRef]

6. Lu, J.; Ge, S.; Ge, L.; Yan, M.; Yu, J. Electrochemical DNA sensor based on three-dimensional folding paper device for specific and sensitive point-of-care testing. Electrochim. Acta 2012, 80, 334-341. [CrossRef]

7. de Oliveira, R.A.; Camargo, F.; Pesquero, N.C.; Faria, R.C. A simple method to produce 2D and 3D microfluidic paper-based analytical devices for clinical analysis. Anal. Chim. Acta 2017, 957, 40-46. [CrossRef]

8. Fu, E.; Ramsey, S.A.; Kauffman, P.; Lutz, B.; Yager, P. Transport in two-dimensional paper networks. Microfluid. Nanofluid. 2011, 10, 29-35. [CrossRef]

9. De Pasquale, G.; Zappulla, L.; Scaltrito, L.; Bertana, V. Numerical and experimental evaluation of SLA polymers adhesion for innovative bio-MEMS. Mater. Today Proc. 2019, 7, 572-577. [CrossRef]

10. Park, C.; Han, Y.D.; Kim, H.V.; Lee, J.; Yoon, H.C.; Park, S. Double-sided 3D printing on paper towards mass

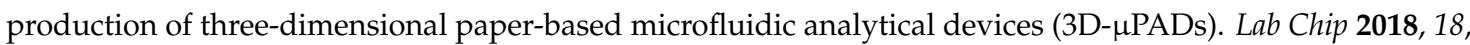
1533-1538. [CrossRef]

11. Martinez, A.W.; Phillips, S.T.; Whitesides, G.M. Three-dimensional microfluidic devices fabricated in layered paper and tape. Proc. Natl. Acad. Sci. USA 2008, 105, 19606-19611. [CrossRef] [PubMed]

12. Liu, H.; Crooks, R.M. Three-dimensional paper microfluidic devices assembled using the principles of origami. J. Am. Chem. Soc. 2011, 133, 17564-17566. [CrossRef] [PubMed]

13. Lea, P.; Keystone, E.; Mudumba, S.; Kahama, A.; Ding, S.-F.; Hansen, J.; Azad, A.A.; Wang, S.; Weber, D. Advantages of multiplex proteomics in clinical immunology. Clin. Rev. Allergy Immunol. 2011, 41, $20-35$. [CrossRef] [PubMed]

14. Gonnelli, S.; Cepollaro, C.; Montagnani, A.; Monaci, G.; Campagna, M.; Franci, M.; Gennari, C. Bone alkaline phosphatase measured with a new immunoradiometric assay in patients with metabolic bone diseases. Eur. J. Clin. Investig. 1996, 26, 391-396. [CrossRef]

15. Chen, S.C.-C.; Tsai, S.P.; Jhao, J.-Y.; Jiang, W.-K.; Tsao, C.K.; Chang, L.-Y. Liver fat, hepatic enzymes, alkaline phosphatase and the risk of incident type 2 diabetes: A prospective study of 132,377 adults. Sci. Rep. 2017, 7, 1-9. [CrossRef] 
16. Zhang, D.; Liu, Q. Biosensors and bioelectronics on smartphone for portable biochemical detection. Biosens. Bioelectron. 2016, 75, 273-284. [CrossRef]

17. Huang, X.; Xu, D.; Chen, J.; Liu, J.; Li, Y.; Song, J.; Ma, X.; Guo, J. Smartphone-based analytical biosensors. Analyst 2018, 143, 5339-5351. [CrossRef]

18. Roda, A.; Michelini, E.; Zangheri, M.; Di Fusco, M.; Calabria, D.; Simoni, P. Smartphone-based biosensors: A critical review and perspectives. Trends Analyt. Chem. 2016, 79, 317-325. [CrossRef]

19. Xiong, Y.; Zhang, Y.; Rong, P.; Yang, J.; Wang, W.; Liu, D. A high-throughput colorimetric assay for glucose detection based on glucose oxidase-catalyzed enlargement of gold nanoparticles. Nanoscale 2015, 7, 15584-15588. [CrossRef]

20. Park, C.; Kim, H.-R.; Kim, S.-K.; Jeong, I.-K.; Pyun, J.-C.; Park, S. Three-Dimensional Paper-Based Microfluidic Analytical Devices Integrated with a Plasma Separation Membrane for the Detection of Biomarkers in Whole Blood. ACS App. Mater. Interfaces 2019, 11, 36428-36434. [CrossRef]

21. Andrachuk, M.; Marschke, M.; Hings, C.; Armitage, D. Smartphone technologies supporting community-based environmental monitoring and implementation: A systematic scoping review. Biol. Conserv. 2019, 237, 430-442. [CrossRef]

22. Lu, Y.; Shi, Z.; Liu, Q. Smartphone-based biosensors for portable food evaluation. Curr. Opin. Food Sci. 2019, 28, 74-81. [CrossRef]

23. Chun, H.J.; Park, Y.M.; Han, Y.D.; Jang, Y.H.; Yoon, H.C. Paper-based glucose biosensing system utilizing a smartphone as a signal reader. BioChip J. 2014, 8, 218-226. [CrossRef]

24. Xiao, G.; He, J.; Chen, X.; Qiao, Y.; Wang, F.; Xia, Q.; Yu, L.; Lu, Z. A wearable, cotton thread/paper-based microfluidic device coupled with smartphone for sweat glucose sensing. Cellulose 2019, 26, 4553-4562. [CrossRef]

25. Ornatska, M.; Sharpe, E.; Andreescu, D.; Andreescu, S. Paper bioassay based on ceria nanoparticles as colorimetric probes. Anal. Chem. 2011, 83, 4273-4280. [CrossRef]

26. Tenda, K.; Ota, R.; Yamada, K.; Henares, T.G.; Suzuki, K.; Citterio, D. High-resolution microfluidic paper-based analytical devices for sub-microliter sample analysis. Micromachines 2016, 7, 80. [CrossRef]

27. Dean, R.L. Kinetic studies with alkaline phosphatase in the presence and absence of inhibitors and divalent cations. Biochem. Mol. Biol. Educ. 2002, 30, 401-407. [CrossRef]

28. Maran, A.; Crepaldi, C.; Tiengo, A.; Grassi, G.; Vitali, E.; Pagano, G.; Bistoni, S.; Calabrese, G.; Santeusanio, F.; Leonetti, F. Continuous subcutaneous glucose monitoring in diabetic patients: A multicenter analysis. Diabetes Care 2002, 25, 347-352. [CrossRef]

29. Collaboration, A.P.C.S. Cholesterol, diabetes and major cardiovascular diseases in the Asia-Pacific region. Diabetologia 2007, 50, 2289-2297. [CrossRef]

30. Yap, C.Y.; Aw, T.C. Liver function tests (LFTs). Proc. Singap. Healthc. 2010, 19, 80-82. [CrossRef]

31. Gaitonde, D.Y.; Cook, D.L.; Rivera, I.M. Chronic kidney disease: Detection and evaluation. Am. Fam. Physician 2017, 96, 776-783. [PubMed]

32. Lin, L.; Gao, Z.; Wei, H.; Li, H.; Wang, F.; Lin, J.-M. Fabrication of a gel particle array in a microfluidic device for bioassays of protein and glucose in human urine samples. Biomicrofluidics 2011, 5, 034112. [CrossRef] [PubMed]

33. Park, J.; Yoon, S.; Kwon, T.-H.; Park, K. Assessment of speckle-pattern quality in digital image correlation based on gray intensity and speckle morphology. Opt. Lasers Eng. 2017, 91, 62-72. [CrossRef]

34. Li, N.-S.; Chen, Y.-T.; Hsu, Y.-P.; Pang, H.-H.; Huang, C.-Y.; Shiue, Y.-L.; Wei, K.-C.; Yang, H.-W. Mobile healthcare system based on the combination of a lateral flow pad and smartphone for rapid detection of uric acid in whole blood. Biosens. Bioelectron. 2020, 164, 112309. [CrossRef]

35. Lim, H.; Jafry, A.T.; Lee, J. Fabrication, flow control, and applications of microfluidic paper-based analytical devices. Molecules 2019, 24, 2869. [CrossRef]

36. Dungchai, W.; Chailapakul, O.; Henry, C.S. Use of multiple colorimetric indicators for paper-based microfluidic devices. Anal. Chim. Acta 2010, 674, 227-233. [CrossRef]

37. Goodman, D.S.; Hulley, S.B.; Clark, L.T.; Davis, C.; Fuster, V.; LaRosa, J.C.; Oberman, A.; Schaefer, E.J.; Steinberg, D.; Brown, W.V. Report of the National Cholesterol Education Program Expert Panel on detection, evaluation, and treatment of high blood cholesterol in adults. Arch. Intern. Med. 1988, 148, 36-69. [CrossRef] 
38. Kadono, M.; Hasegawa, G.; Shigeta, M.; Nakazawa, A.; Ueda, M.; Yamazaki, M.; Fukui, M.; Nakamura, N. Serum albumin levels predict vascular dysfunction with paradoxical pathogenesis in healthy individuals. Atherosclerosis 2010, 209, 266-270. [CrossRef]

39. Mohankumar, N.; Ranjan, P.; Kumari, A. Drug-induced liver injury: Diagnosing (and treating) it early. J. Fam. Pract. 2015, 64, 634-644.

40. Ceriotti, F.; Boyd, J.C.; Klein, G.; Henny, J.; Queralto, J.; Kairisto, V.; Panteghini, M.; IFCC Committee on Reference Intervals and Decision Limits (C-RIDL). Reference intervals for serum creatinine concentrations: Assessment of available data for global application. Clin. Chem. 2008, 54, 559-566. [CrossRef]

41. Sugita, S.; Sasaki, A.; Iwaki, K.; Uchida, H.; Kai, S.; Shibata, K.; Ohta, M.; Kitano, S. Prognosis and postoperative lymphocyte count in patients with hepatocellular carcinoma who received intraoperative allogenic blood transfusion: A retrospective study. Eur. J. Sur. Oncol. 2008, 34, 339-345. [CrossRef] [PubMed]

42. Jimba, S.; Nakagami, T.; Takahashi, M.; Wakamatsu, T.; Hirota, Y.; Iwamoto, Y.; Wasada, T. Prevalence of non-alcoholic fatty liver disease and its association with impaired glucose metabolism in Japanese adults. Diabet. Med. 2005, 22, 1141-1145. [CrossRef] [PubMed]

43. Walker, H.; Hall, W.; Hurst, J. BUN and Creatinine-Clinical Methods: The History, Physical, and Laboratory Examinations; Butterworths: Boston, MA, USA, 1990.

44. Evans, E.; Gabriel, E.F.M.; Coltro, W.K.T.; Garcia, C.D. Rational selection of substrates to improve color intensity and uniformity on microfluidic paper-based analytical devices. Analyst 2014, 139, 2127-2132. [CrossRef] [PubMed]

45. Gabriel, E.F.; Garcia, P.T.; Cardoso, T.M.; Lopes, F.M.; Martins, F.T.; Coltro, W.K. Highly sensitive colorimetric detection of glucose and uric acid in biological fluids using chitosan-modified paper microfluidic devices. Analyst 2016, 141, 4749-4756. [CrossRef]

46. Evans, E.; Gabriel, E.F.M.; Benavidez, T.E.; Coltro, W.K.T.; Garcia, C.D. Modification of microfluidic paper-based devices with silica nanoparticles. Analyst 2014, 139, 5560-5567. [CrossRef]

Publisher's Note: MDPI stays neutral with regard to jurisdictional claims in published maps and institutional affiliations.

(C) 2020 by the authors. Licensee MDPI, Basel, Switzerland. This article is an open access article distributed under the terms and conditions of the Creative Commons Attribution (CC BY) license (http://creativecommons.org/licenses/by/4.0/). 